\title{
Teaching Aesthetics in Interaction Design: Attempt One
}

\author{
Sus Lundgren \\ Interaction Design Collegium \\ Department of Computer Science and Engineering \\ Chalmers University of Technology / University of Gothenburg \\ SE-412 96 Göteborg, Sweden \\ sus.lundgren@chalmers.se
}

\begin{abstract}
The issue of aesthetics is complex, and the discussion on how to apply it to interaction design has hardly begun. Hence, there is not much written on how to teach this subject; this paper consists of a suggestion. Here, I will describe my work with the course Aesthetics of Interaction, and my initial intentions behind it. The course consisted of lectures, literature discussions, excursions, exercises and feedback sessions, and the examination form was to hand in a portfolio. It turned out to be a creative and interesting journey with highlights such as the intricacies of designing playful interaction, evoking angst, mimicking Word's design, adding time to art, redesigning the Office assistant and more. These and the other parts of the course will be analyzed and discussed in relation to their learning outcomes in terms of my observations and the students' own comments. Consequently, possible changes and improvements will also be discussed.
\end{abstract}

\section{Categories and Subject Descriptors}

H.5.2 [Information interfaces and presentation]: User Interfaces - Evaluation/methodology, Theory and methods; K.3.2 [Computers and education]: Computer and Information Science Education - Computer science education, Curriculum

\section{General Terms}

Documentation, Design

\section{Keywords}

Teaching, didactics, aesthetics, interaction design

\section{INTRODUCTION: AESTHETICS IN INTERACTION DESIGN}

Aesthetics as a concept was founded in 1750. Up until then, the notion did not exist or rather, it was equal to artistic beauty - a beauty based on proportions, harmony and symmetry for the most. Still, the terms "aesthetic" and "beautiful" are considered interchangeable by most people. However, when the concept was founded by Alexander Baumgarten in his book "Aesthetica" in 1750, he attributed the word with another meaning; it was that which could be experienced and thus known via the senses. [27]. In this he tried to propose a new science, but the notion of aesthetics was quickly connected to art and judgment of taste by contemporary philosophers like Kant and Hume.

In the latest century however, different art styles and forms have exploded, and so has the view on aesthetics; every art form or direction needs its own values. Two striking examples are for instance the Bauhaus - very functional with "less is more" as guiding star - and Memphis, whose aesthetic ideal was to provoke by breaking all rules and combining materials and shapes as awkwardly as possible [29]. Albeit quite opposite, both views are legitimate. This discord brings with it both freedom, inspiration and confusion - and the right for everyone to invent their own aesthetic ideal. The whole process has been eloquently summarized by Udsen and Jørgensen [28]:

"Although aesthetics is far from a new invention, it has never achieved a commonly accepted foundation as a theoretical discipline. Subsequently, the task of self-definition is one of the most stable features of the discourse in aesthetics. "

As in any other subject, interaction design features an ongoing discussion on what interaction design aesthetics are. The interest for this area is rather new though; most papers and books discussing it are from 2000 or later. It seems that this focus on aesthetics and experience has in part succeeded and replaced the focus on usability.

In the 1930ies Dewey presented a pragmatic view, focused around aesthetics as being the result of having an experience [5], and this idea about aesthetics lying in the user's experience has been taken up in the interaction design community by for instance Shusterman, Petersen and others [cf. 22, 26] who advocate designing rich experiences involving as many senses as possible. Others disagree; there are also suggestions that interaction aesthetics is related to temporality, and the expressions of the object itself $[12,13,14,18]$. Here we see a slight connection to another group of researchers [16, 19, 24] who see the notion of "personality" or character as a basis for an aesthetic whole. Somewhere in between these opinions is the idea bout interaction aesthetics manifesting themselves in the gestalt of interaction, as proposed by Lim et al [cf. 17]. Yet another group apply theories from art or other socio-cultural contexts [3, 20]. To them, aesthetics is much about creating a pleasing experience. Others, like Dunne, Gaver and their like-minded $[6,7,8,10]$ work with explorative design in order to explore new aesthetic dimensions. They also often experiment with ubiquitous computing and the design, and aesthetic ideals, for these new kinds of devices. On the other hand traditionalists like Jakob Nielsen for instance, hail ultra-functionality as the one aesthetic ideal.

Hence the subject is complicated, unclear and teaching it is rather unexplored - hence my undertaking to design and run the course Aesthetics of Interaction, which will be described in the rest of the paper. 


\section{METHODOLOGY}

This paper is based on an action research project within an education context [cf. 2, 4, 9, 15, 25]. Hence, the observations are based on the authors' seven years experience of teaching interaction design. Although the course in itself was new, some of the exercises have been tried out before, which means that the have been tested by several groups of students on several occasions. Data was collected in four ways; from all the written material the students handed in, from learning incidents the students reported, from a concluding questionnaire, and from the author's own observations.

\subsection{Setting}

The course, Aesthetics in Interaction, ran in late fall 2008. It is actually a Ph.D.-course, open for master students in interaction design, but only master students took it in this first version. It was an eight-week course worth 7.5 credits, and ten students took it. Out of these ten only five were Swedish - in addition there was one student from Germany, Portugal and Iran respectively, and two from China. Four of the students were female, the rest male, and nine of them had had myself as main teacher in one previous course called Graphical Interfaces (early fall 2007) and as assistant teacher in another course called Interaction Design Project (spring 2008); the latter course contained a two-week introduction to aesthetics which I was responsible for. Hence the students and I knew each other, and I have also had the opportunity to see how the students have evolved over the last 18 months.

\section{CURRICULUM}

Given the current discord on aesthetics in interaction design, my approach to the course was to just present the different opinions and then let the students themselves choose the view that suited them best. Thus, the goal of the course explicitly was that the students should develop their own view on aesthetics, and, more importantly, means to attain it. Consequently, I tried to be rather neutral in my teaching, not explicitly teaching my own view.

Hence, the course consisted of a few lectures and related excursions to museums paired with a series of exercises spanning over different aesthetical issues like form, material, interaction, temporality and behavior. The examination form was to hand in a portfolio containing revised versions of some of the exercises, two new exercises and an essay entitled "My view on aesthetics of interaction".

Below I will describe the contents of the course. In order to avoid confusion I choose to discuss and reflect over each element directly in this section, rather than in the discussion. The quotes enclosed come from emails that the students have written to me when asked to report what they found the most interesting element of one certain day. Again, there were only ten students in the course. In between them they sent in thirty five such comments. Also, answers from the course questionnaire are used as a basis for evaluation.

A comment on comments: In order to keep the student's anonymity I've given them fake initials after the comments. I've also fixed grammatical errors (if possible; sometimes it was unclear) and spelling errors in the quotes.

\subsection{Lectures}

There were only four lectures; one on the history of aesthetics in general, from ancient Greece and onwards; one on the history of industrial design; one on aesthetics in interaction design and one on gestalt and character design. The lectures also contained a suitable small design task or discussion topic.

Reflection: In retrospect, focusing half of the lectures on historical overviews was unnecessary; the first lecture could easily become a smaller part of the second one.

Consequently, more lecture time should be spent on the current situation. As one student wrote in his learning incident for the third lecture: "The not so good: hard to engage in discussions when new concepts are "thrown" at you all at the same time with little time to take it all in." (GF)

As for the design tasks and discussions these were more rewarding; since the class was so small we could have lively discussions where most students participated.

\subsection{Literature}

In an earlier course, the students had gotten an introduction to aesthetics, in which they read texts by Alberti, Hallnäs and Redström, Lim et al, Monö, Petersen et al. and Ziff [cf. 1, 13, 17, 21, 22 and 30 respectively]. Hence, the literature for Aesthetics of Interaction consisted of texts by Dewey, Gelernter, two texts by Hallnäs and Redström, Janlert \& Stolterman, Manovich, Reeves \& Nass, Udsen \& Jörgensen, and, again, Lim et al [cf. 5, 11, 12, 14, 16, 20, 24 and 17 respectively]. Each text belonged to a certain lecture, and it also had 2-3 questions associated with it. The students were divided into literature groups of 3-4 students, and they had to divide the questions amongst them so that everyone got two. The answers were to be handed in before the actual lecture, and in association with the lecture, the students also sat down in groups and discussed the answers to the questions.

Reflection: Having literature questions had two points, firstly to point out what was important in the texts and secondly to force students to write answers to two of the questions. Although this worked, and actually made the students read the texts, they of course took two questions associated to the same text, meaning that they only read one of the texts properly. Hence, the "discussion" on each question was not so much a discussion, but rather a presentation but at least students got some insight in the text they had only skimmed. Making students read texts, and reflect over them, seems to be an eternal problem. There was one exception to this however, namely the text by Lim et al [17]. Here, I wanted to discuss the different interaction gestalt attributes they suggest in class, so the students were told to pay specific attention to them because of this. Indeed, we had a very good discussion on the attributes in class, and I also ran a quick group discussion task based on this, which worked very well. It may be that this is the way to go.

In the course evaluation, only two out of nine students thought that the literature was an important element in the course. So either the texts were badly chosen, or this teaching form did not work. Hopefully a more direct coupling between lectures and literature will help. 


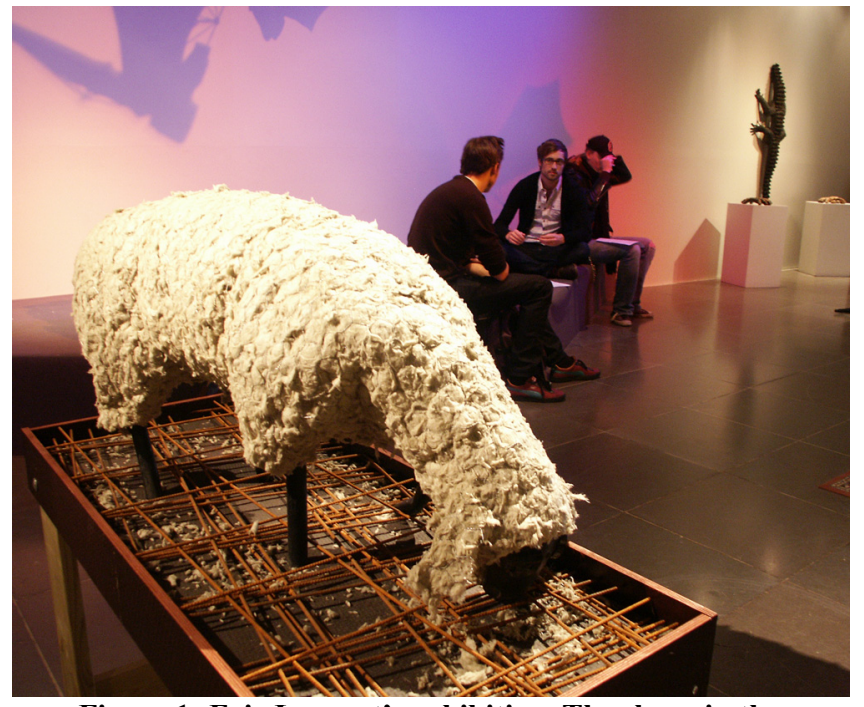

Figure 1: Eric Langert's exhibition. The sheep in the foreground is made out of building materials, like insulation

\subsection{Excursions}

Throughout the course we did four excursions. The first one was to the local design museum which has an excellent exhibition on the history of industrial design. We did the visit directly after a lecture on the history of industrial design (and its aesthetic ideals). The second one was a visit to a temporary exhibition by artist Eric Langert (see Figure 1) who takes everyday things and turns them into animals ${ }^{1}$; the aim of this excursion was to discuss form, material and why we like some things and dislike others. At this exhibition each student also had to choose the animal he or she liked the most and the least and we then examined everyone's choices and discussed them. The third excursion was also a temporary excursion, at Kulturen in Lund, this time on Chinese culture - an attempt to study aesthetics of another culture, but unfortunately the guide was more interested in talking about historic events than about art. The fourth excursion went to the Museum of Sketches in Lund, showing archives of public art. Here "sketches" of any kind of public art are shown, i.e. not only paper sketches but also models etc.

Reflection: According to the student's comments three of the excursions (all but the one to the Chinese exhibition) were definitely worthwhile and very inspiring. The first clearly excursion served to exemplify what had been taught in the lecture:

"The most interesting thing was visiting the museum, and found the things what exactly you have talked about in the lecture. It is really nice, and new for me. It makes me understand much better." (VN)

"Great to actually see the products in real life, it gives a very different experience compared to only see pictures. Nice to have a guide from the museum." (LN)

"Going to the museum to get direct feedback on the lecture was very inspiring. Sometimes things look different in pictures and in

\footnotetext{
${ }^{1}$ To see Eric Langert's wonderful creatures, visit http://www.langert.se/, choose English and then "My animal park"
}

reality, an one can really see how the designers have been inspired by each other." (FT)

The second excursion, the one with the animal sculptures, was also considered valuable, partly because the discussion we had where the students had to articulate which pieces they liked and disliked and why.

"Very interesting. Made me realize how hard it can be to actually now WHY you find something to be aesthetically pleasing. Also I came to think of if we have different views on aesthetics for different types of design, [...]. Finally very clear that we all have different opinions on aesthetics, or at least don't agree on what is beautiful or not." (HP)

"What I learned today was that I'm starting to believe that aesthetics and form are highly related. Also materials and combination of elements are playing an important role in what defines something as aesthetically pleasing. [...] So to make an aesthetically pleasing artifact, there should be an emphasis on at least one factor (material, form, combination of elements and etc.) and a creative use of that in the design." (PM)

Unfortunately, the Museum of Sketches is a three-hour train ride away, so in order to make the trip worthwhile the unsuitable Chinese exhibition that was in the same town, was "thrown in". In retrospect this was a mistake - it would have been much more rewarding to spend the whole afternoon at the Museum of Sketches instead, since it was so inspiring to the students.

"The Museum of Sketches - the most interesting of the two. Very impressing to see all the works. I don't know why, but I have never reflected on creating a painting or a sculpture as that kind of sketch process before. The visit really opened up my mind =) The museum was very inspiring and definitely something I'm very glad that I now have seen. "(HP)

"The Museum of Sketches was awesome - really cool idea for a museum and very inspiring. " (GF)

\subsection{Exercises}

The exercises made a shift from being more industrial design-like tasks over to interaction design tasks. The rationale for this was that few of the students had any schooling in form giving and materials, and thus needed some kind of introduction to this. The exercises were as follows (for full descriptions, see http://www.cs.chalmers.se/ lundsus/lundgren_aoi_exercises.pdf

\subsubsection{Super Hero Gadgets}

Here, the task was to create a super hero logo and logo-gadget (e.g. a magic ring with the logo on it, or a belt buckle). The aim of the task was to work with symbols, expression and gestalt and the idea was that student's should get an understanding of the coupling between form, meaning and interaction. The exercise was carried out in pairs.'

Reflection: This task simply didn't work, probably because most students weren't trained in creating symbols and logos. In addition there was much confusion about the gadget and what it should "do". In addition, the interaction-part of the task was very small, it was mostly about graphic design. Hence, the exercise will be taken out of the course.

"It was a fun exercise, but I'm not sure if I really learned something new." (LN) 


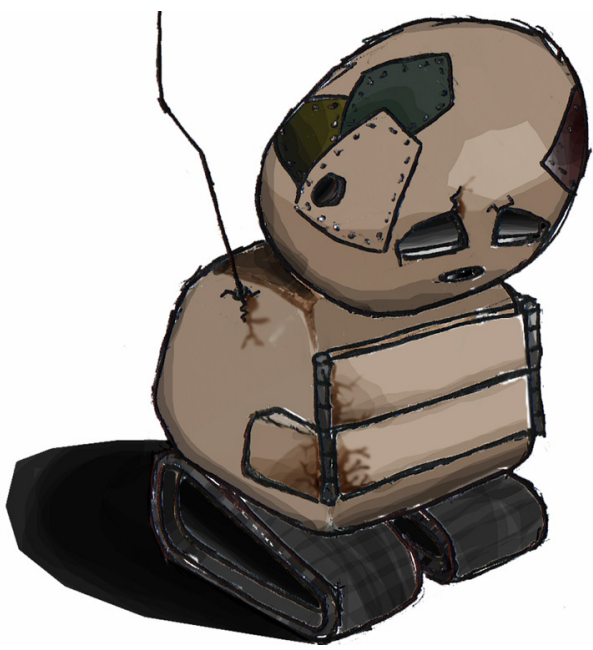

Figure 2: In Exercise 3 Olof Göranson designed the "Mental Patient Robot Ticket Vending Machine" which expresses angst by hiding from its users, banging its head against the wall, rocking back and forth etc. Payment is pushed into its mouth against its will. (Illustration by Olof Göranson)

\subsubsection{Cartoon}

Here, the task was to take lots of photos and turn them into a cartoon, exploring the rich language of posture, image cropping and use semantics and symbols and tell a story on a limited space. The exercise was carried out in pairs.

Reflection: Albeit this task was rather popular, and the students learned what they were supposed to learn, its contents are probably to far from the core contents of the course. Both this exercise and Super Hero Gadgets had been added to help inexperienced students explore a graphic language - but this cannot be taught in two exercises anyway, so they will both be taken out.

\subsubsection{Designing Emotions}

Here, the task was to create a ticket vending machine that either expressed or evoked angst. The aim was to explore how different emotions can be created, utilizing aspects of form, material and interaction, and the hoped learning outcome was that students should learn how to create an aesthetic aimed at evoking or expressing a certain feeling.

Reflection: This seemed to be an exercise that made a strong impact; during the final presentations, when students were encouraged to talk about the design processes that they found most interesting, three students (out of nine) mentioned this design task. Choosing angst as a feeling works well since the feeling is so extreme, and thus somehow inspiring. Also, it is interesting to compare the machines that evoke angst with those that express angst since the task becomes more or less opposite.

"I learned that [...] designing the environment (the context) can sometimes be even more important than the actual object/subject being designed." (PM)

"I liked to approach the design by defining colors, natural phenomena, tools etc. which would be connected to "angst". This strategy seems to be useful, if one wants to express specific emotions with a design object." (LN)

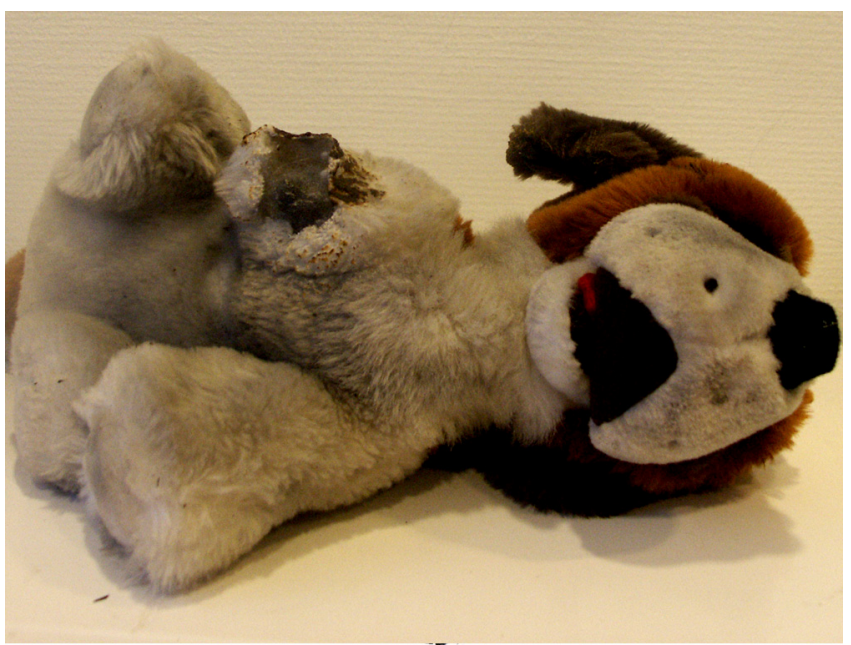

Figure 3: In Exercise 4 Kalle Landin designed this plush puppy. It is burnt, mutilated, wet and muddy and it is designed to evoke sad interaction, since its users are supposed to associate to the puppy's owner, a child killed in the fire that destroyed the toy.

\subsubsection{Interaction Themes \& Things}

The aim of this task is to focus on the interaction per se. Each student got a word (like jealous, careful, happy, sad etc.) and the task was to create an object that invoked that type of interaction. I.e. when one looked at the person interacting with the object the person should seem to be feeling that certain feeling. However the users do not have to - but may - experience the feeling. E.g. interacting with a boxing ball is an aggressive interaction per se, even if the boxer does not feel angry.

Reflection: Although this may seem like a pseudo-task it can actually occur in real life, as when our design group was asked to design interactive installations for a museum; in that case one wants the users to act in an interested or amused way, in order to tempt new users to try out the installations. Anyhow, this was the hardest exercise of them all, but also the most fruitful one. Our students are used to attacking problems starting out from either function or a general form (e.g. the general form of a web page), and incorporating interaction in it. They hardly ever start the design process with aiming for a certain type of interaction per se, and doing this was hard for them, but also enlightening.

"I learned to think about expressions of interactions themselves." $(L N)$

"I really liked the exercise because it made me think from another perspective. [...] The exercise clarified how hard it can be to design a specific way of interacting, but it also made me think of how important it is that a interaction designer thinks of the consequences a design will have for the way we will interact with it." $(H P)$

However a problem was that the words were not equal, from a design perspective. The words annoyed, energetic and careful were too easy, whereas sad and playful were harder. The student having playful commented that it is easy to design something that is playful, or something one can play with, but what is playful interaction like, really? Words that worked, and that probably will be reused were jealous, loving, shy, hysteric and content. 


\subsubsection{Temporal Paint}

This task focused around different ways to view and use time as a central part in design. First, students got an introduction to different ways to "use" time, e.g. as in the movies Memento or Pulp Fiction (where time is non-linear), in TV-series like 24 (where one minute represents one minute, and where different events are sometimes juxtaposed) and in games like Braid (where players have to move back and forth in time in order to succeed) and World of Warcraft (where the online world and the events in it continue regardless of whether you are logged in or not). Using this as inspiration, the students were encouraged to design a simple drawing program - the only thing users could do was to draw lines - and incorporate time and changes over time in their design. After yet another theoretical discussion the students got to try out different version of such drawing programs, which had been developed by an older student, Theo Hultberg, in his thesis. They can be found at: http://demo.iconara.net/ex/. This was followed by an analysis of the different applications, how time was used in them and how this affected interaction.

Reflection: In this exercises the students did not actually design anything, they only came up with concepts. I think it is necessary to try and implement temporal aspects in order to become more aware of them, which means that the task has to be changed somehow. In any case, this focus on time was an eye-opener for some students:

"It is actually the first time ever, I really thought on temporal aspect. It brought me some ideas how to express time aspects in design of interaction. " $(V N)$

“Also a very interesting exercise." (HP)

"It was really interesting and new for me to think of different time frames and the way they could be used in the design. I have been used to only think of timelines passing one by one in a sequence in real-time and all my designs have been progressed in that way on real-time, but after today's lesson, I learnt that I could make the past constantly affect the present." (PM)

\subsubsection{Informative Art}

The aim of this task is to explore how temporal aspects of design affect the expressions of a certain object. It is based on a paper [23], where the idea is to turn art into a changing display that shows some kind of information, however in a quite disguised way since it should still look like an art piece. The students first came up with their own abstract artistic style and then turned into a prototype of an informative display showing some kind of information, like the weather, the use of a printer or of our coffee machine.

Reflection: I have run this exercise several times, but in a shorter version where student's only come up with sketches and not prototypes, and where they get a few sample paintings from an artist, whose style they have to use (e.g. Josef Albers, Mark Rothko and Theo van Doesburg). This worked better than letting the students come up with their own style, because then there is an existing framework and some "rules" to cling to when discussing the prototype. You can say "Oh, but if you apply time in this way, your painting will look like this at noon every day, and that is not very Josef Albers-like." This is important, since the interesting part in this exercise is to discuss time-related things like updating, whether the painting shows the current condition or the last $\mathrm{x}$ hours or days or perhaps even a forecast of the upcoming $\mathrm{x}$ hours etc. and how this affects how the painting looks. If the students make their own style they can say that any look is ok, or, as in some cases, the students may create an art style that is not abstract enough. One student created a kind of machine-art; beautiful, black and white machinery with different propellers and bolts and other parts moving, the movement coupled to information. But it turned out that this was to life-like; not everything could be mapped to this kind of art e.g. wind speed works, but not necessarily types of coffee, for this the art is not abstract enough.

\subsubsection{Design the Apple}

The aim of this task is to study an aesthetic in terms of look\&feel plus interaction style created by someone else, and practice in applying it. Hence, the students were asked to analyze a software like Google or iTunes or Microsoft Word and then create a bike of coffee machine with the same look and feel and means of interaction.

Reflection: This task worked very well since the main focus was on analysis and transfer of interaction. The outcomes were also very creative, e.g. the Word-bike that would automatically brake at a red light but also would decide which way was the best one to take, regardless of the user's wishes. However it would probably have fit better earlier in the course due to the strong focus on analysis. Regardless, the students thought this was one of the most interesting and instructive exercises according to the course evaluation.

\subsection{Feedback sessions}

Each exercise was followed by an extensive feedback procedure. Firstly, each student had to write feedback to one other student, so that everyone got some feedback on paper. Secondly, we ran a one-hour feedback session in class, where each student presented their feedback on someone else's work whereafter this person could agree, clarify or counter-argue. Then, the rest of the participants could give feedback too.

Reflection: These feedback sessions were highly appreciated.

"I really like the feedback sessions, they help me improve my design in a good way" (PM)

As mentioned, the ten students came from five different countries, and cultural differences often surfaced during these discussions (e.g. the notion of angst differed somewhat). Also it was useful for the students to "try out" their designs on the group.

"I started to think about how to express my culture [...]. However, I don't know whether I succeeded or not. But it is interesting to see how the reactions are. " (VN)

After the exercise "Interaction Themes \& Things" we had a guessing contest where they should try to assign the right word to the right object, and this was very rewarding. The students knew about it in beforehand, and they used it as a kind of measurement:

"At the same time I must say that it was a very hard exercise, and it will be very interesting to see if anyone guesses the exact correct word on Tuesday..." (HP)

In the course evaluation, six out of nine students checked the feedback sessions as being something they had learned the most from.

"Feedback very giving." (Course evaluation) 
"Feedback sessions, [it is] really useful to see and reflect on the work of others." (Course evaluation)

\subsection{Examination: portfolio}

The examination was not a written exam; instead the students had to hand in a portfolio containing improved and extended versions of three of the above exercises, one essay entitled "My view on Aesthetics of Interaction" and two new exercises carried out without supervision. There were three portfolio exercises to choose from, so one could be left out. All of the contents are described in detail below.

Reflection: It happens to be my personal opinion that a practical subject should be examined practically; that is why I chose this form, rather than just having the essay. I think it works well; it gives a good estimate of the students' design skill.

As for the students, they were very positive in the course evaluation; all but one ranked it as being good or very good (the two highest judgments).

\subsubsection{Improved and extended exercises}

The students got to choose three of the exercises they had carried out in class. These designs were improved according to the feedback they got, and in addition they had to design something more, e.g. another cartoon, informative art pieces showing some other information etc.

Reflection: The approach to this was very different. Some students saved time by picking their most successful exercises. Others used this as a chance to redeem themselves. Others simply chose the ones that they had liked the most.

"Good to improve exercises from earlier part of the course" (Course evaluation)

Consequently, this part seemed to work, also from my course evaluation perspective, it was interesting for me as a teacher to see the improvements.

\subsubsection{Portfolio exercise: Calculator on the Runway}

The aim with this task was to work with "personality" as a concept for creating a working aesthetic. The students were asked to design three different calculator prototypes, each with its own personality that should appear in look, feel, behaviors and functions.

Reflection: Although I consider this task to be very promising it did not work out as well as intended. One reason for this was that this was one of the portfolio exercises, i.e. the students did not get any supervision. Another was that even if the notion of "personality" as a tool for design had been discussed in the last lecture, it had not been practiced in any previous exercise. Hence students tended to get stuck on look\& feel rather than actual behavior of the calculators. And thirdly, the students did not create any elaborate personalities, they either settled for stereotypes ("One calculator is made inspired by a shy person stereotype. This person is very introvert, doesn't want to get noticed and expresses himself very gently. It may also be hard to actually hear what he is saying since he talks so quietly." (MN)) or fictional characters like Homer Simpson. This is not a problem per se, other than that these personalities are rather shallow, not inspiring any complex behaviors. Consequently the exercise may well be used, but with clearer instructions, probably earlier in the course and directly coupled to the lecture on personality.

\subsubsection{Portfolio exercise: The new office assistant}

Here, the aim is to study an aesthetic, analyze it and improve it significantly using common sense and the notion of personality. The task is based on Microsoft's Office assistant, the paper clip, which can also be changed to a dog, cat, wizard etc. regardless, it does not always behave in a logical/natural way when the user does something, e.g. when asking a question the dog sits down at a desk and takes a note, whereas a real dog would probably start sniffing around to find whatever you are searching for. The task is simply to improve an existing assistant or to create a new assistant-being that acts more in accordance with its nature.

Reflection: This task worked very well. It really forced the students to look for the coupling between different assistant behaviors and users' actions. During the final presentations, when students were encouraged to talk about the design processes that they found most interesting, four students (out of nine) mentioned this design task and how they had analyzed different animals in order to create suitable actions.

\subsubsection{Portfolio exercise: The cube}

This was the freest of all exercises; the aim was simply to follow one's own aesthetic codex. The task was to create an application for a currently non-working artwork in [our city]; a $2 \times 2 \mathrm{~m}$ cube with opaque glass sides. Under ground below it, four video projectors are mounted in a control room, which means that any digital content can be projected onto the cube's four sides.

Reflection: Albeit inspiring and fun in many ways, this exercise is too open, and almost impossible to compare and to grade. In the end grading tends to be based on how rich the concept idea is, and whether it will "work" under the given circumstances.

\subsubsection{Essay: My view on Aesthetics of Interaction}

The aim of this essay was simply to force the students to form their own opinion on what they considered to be their own aesthetic values, and how to attain them. As a preliminary exercise all students were asked to articulate their view in terms of three levels; overarching goals (e.g. "functionality" or "positive experience"), overarching guidelines (e.g. "form follows function") and concrete guidelines (e.g. clarity, minimalism, geometric shapes). These were discussed in class. The students were also asked to reflect upon related issues, like the (possible) difference between aesthetics of interaction in general.

Reflection: Three out of nine students considered the essay to be an important part of their learning process. The others may not have appreciated it, but I judge it to have been important nevertheless. However, such an essay is hard to grade.

\section{ANALYSIS}

In this section the overarching issues not covered by the Reflection-sections in part 3 will be discussed.

\subsection{Learning outcomes}

As mentioned, the reflections in section 3 are based on four sources:

- The learning incidents students sent me throughout the course - however the last ones dealt with the exercise Temporal Paint, after that everyone got overwhelmed with portfolio work.

- The course evaluation, which was a questionnaire that nine of the ten students answered. 
- The written material that the students handed in; essays, feedback, answers to literature questions.

- My own observations.

The first two sources have already been cited heavily. However they do not answer the most burning question; what did the students get out of the course? According to the evaluation they were quite satisfied; the course got an overall grade of 4.5 (5 being the highest), and five students claimed to have learnt more than they expected. But what? The answer lies in the essays they handed in. Since the topic was My View on Aesthetics of Interaction, it forced the students to examine the subject, and they certainly did. In their essays they built their argumentations on a mix of the literature they had read, own opinions and, just as importantly, on matters discussed in class or things experienced in the exercises. As mentioned, most of these students (but in a larger class of 38 students) had gotten a two-week introduction to aesthetics in an earlier course. Here too, the students had to write an essay on their view on aesthetics, but these 38 essays were in general much more shallow than the essays written after this course.

This strongly indicates that the subject is intricate and that a brief approach mainly based on reading literature will not suffice; a critical discussion and above all practical experience seems to be necessary. Currently, it is hard to sort out which parts of the course led to the most insights, or to which insights, other than the different comments already presented. This first iteration of the course has only served to show one way to teach the subjects; later iterations may help in creating more overarching guidelines.

\subsection{Time issues}

An issue related to the exercises was that students typically spent several extra hours the next day to finish them. Either, I've underestimated the tasks (each task was scheduled to take five hours) or the students are perfectionists. It seems to be a little bit of both. One possible solution would be to assign more hours to the tasks (working 9-17 instead of 10-16) and/or clearly state that the tasks have to be handed in at the end of the day. I'm not really fond of the latter constraint, since it is unfair to those who work slow, or who take some time in getting a good idea to work with.

In the questionnaire, six out of nine students complained that the course took too much time. It may be an idea not to add extra portfolio tasks. Another idea would be to force students to choose and improve exercises earlier in the course, to even the workload, but that would limit their choices. On the other hand students almost always complain about courses being to time-consuming, so maybe this complaint can be ignored.

\subsection{Grading}

An issue for me, but not for the students was grading. The typical grading scale at Chalmers University of Technology is fail, 3,4,5. This of course makes grading much more complicated than just fail/pass. Overall grading was complicated, since the course evolved around the students finding their own view on aesthetics. How can one compare and grade the work of someone believing in functionalist and minimalist design with that of a person whose aesthetic ideals is emotional response? This issue was partly foreseen by letting the students write the essay about their view on aesthetics of interaction and then partly base the grading on what they claimed was important in the essay. E.g. a student targeted very much versus functionality as an overarching ideal would partly be graded on how functional his or her designs were. Still, grading was very tricky. However we had a number of class discussions on what aesthetics were and what was important, and one word that kept reoccurring was consistency in relation to an and aesthetic ideal. So, of the aesthetic ideal in itself is inconsistency, then the design must be consistently inconsistent, just as if minimalism is the ideal, the design has to be consistently scarce. Another important theme seemed to be weighing between function, ease of use and an (other) aesthetic ideal; in their essays all but two students discussed this and commented that in some products, e.g. medical equipment, the superior goal must be to design something that never fails and is easy to use, whereas in other products, one can allow oneself to toy with aesthetic ideals like playfulness or provocation. Another thing that we discussed was that some things or genres have their own special aesthetics like cartoons or products from a certain company, in which case one as a designer has to adapt to the existing aesthetic idea. These shared insights became the basis for grading.

\subsection{Changes and improvements}

The next time around, the course will most likely be improved by refocusing lectures on the current situation, and the literature will be discussed in class in direct relation to the lectures. In addition, the set of exercises will be renewed, and a new stance will be taken, as explained below.

\subsubsection{Exercises}

The three exercises the students themselves found most instructive (at least according to the course evaluation) were Designing Emotions, Interaction Themes \& Things and Design The Apple, and they did not learn anything at all from Super Hero Gadgets or The Cube. This is in line with my own observations and conclusions as mentioned in part 3.6.

As mentioned, the original intention was to make a transition from traditional form/material-related tasks to tasks focusing on interaction. However the students either know or did not know about materials and form-giving. In the first case the two first exercises were unnecessary, in the latter, not enough. Hence it is better to only have exercises focusing on interaction, expressions and temporal aspects. Also, a better order is probably Design The Apple (since this a quite easy task evolving around analysis), Designing Emotions, Interaction Themes \& Things (since these focus on the connections between form, material and interaction), one or two exercises focusing on temporality (e.g. Informative Art in its original version with given artists), and finally The New Office Assistant and Calculator on the Runway (to cover consistency in behavior and personality).

\subsubsection{Lost without a compass?}

The hitherto mentioned changes are comparatively small and well motivated by comments and observations. However I have decided to make one major change next year. As mentioned in the first paragraph of section three, my intention was to neutrally present the existing views on aesthetics in relation to interaction design, and then let the students freely choose their own opinion. Although I still think that students must find their own opinion, I have found that it can be helpful to give students a starting point, from which they can find their path, rather than just dumping them in the void. After two weeks and three of the four lectures, the students were quite frustrated about the whole issue and had problem formulating their standpoint. We discussed it after one 
lecture, and I let everyone write key values on Post-Its. This democratic definition stated that aesthetics of interaction is a matter of (creating?) "a positive individual experience of an artifact which is a Gesamtkunstverk characterized by usability, rhythm, richness and freedom of interaction." It's a sprawling definition lacking several key values that one may want to have, and sure enough the student's final opinions as expressed in the essays differed from this, but still I think it helped their thought processes. It is easier to have an opinion on an existing definition than to invent one from scratch. Also, this counters another issue because it's easy to say that something is neutral, e.g. one's teaching, or the texts one chooses as literature for a course, but are they really? Can they ever be?

\section{CONCLUSION}

In the next version, the course Aesthetics of Interaction will keep successful parts, like feedback sessions and most exercises. Lectures and literature will be improved. However, this next version of the course will start with some kind of definition/discussion on what I think that aesthetics in relation to interaction are, and then the students can modify that as they wish. Also, we will look upon aesthetics as being the strive for consistency in relation to a certain ideal (e.g. symmetry, or provocation, or functionalism, or whatever). Lastly, there will be a stronger focus on the specific tools that we as interaction designers have to our disposal when designing; temporality and behavior, and how they affect this consistency.

\section{ACKNOWLEDGMENTS}

I would like to thank all my students for participating in my course and so generously sharing their insights with me; Susanne Edevåg, Erik Fagerholt, Olof Göransson, Matthias Klein, Karl Landin, Magnus Lorentzon, Laleh Omalaki, Carla Sarvaviva, Dong Sun and MinJuan Wang.

\section{REFERENCES}

[1] Alberti, Leon Battista (1435): On Painting. This medieval text can be downloaded from http://www.noteaccess.com/ Texts/Alberti/ (Retrieved 090108)

[2] Bassey, M. (1998) Action Research for improving educational practice, in Halsall, R. (ed.) Teacher Research and School Improvement: Opening Doors from the Inside, Open University Press, pp 98-108.

[3] Bolter, J. and Gromala, D. (2003) Windows and Mirrors: Interaction Design, Digital Art, and the Myth of Transparency, MIT Press.

[4] Carr, W. and Kemmis, S. (1986) Becoming Critical. Education, knowledge and action research, Falmer Press Ltd.

[5] Dewey, J. (1934): The Aesthetic in Experience Excerpts from Art as Experience, first published by G. Putnam's Sons in New York 1934. This summary consists of pages 13, 16-17 and 35-50 of the original version and was published in Feagin, S., and Maynard, P. (Eds.) Aesthetics, Oxford University Press 1997

[6] Djajadiningrat, J.P., Gaver, W.W. and Frens, J.W. (2000). Interaction Relabelling and extreme characters: Methods for exploring aesthetic interactions. Proceedings of DIS'00, ACM, New York, pp. 66-71.

[7] Djajadiningrat, T. et al (2004) Tangible products: redressing the balance between appearance and action. Personal and Ubiquitous Computing, Vol. 8 , No. 5 (September 2004) pp. 294 - 309

[8] Dunne, A. (1999) Hertzian tales. Royal College of Art Computer Related Design Research, London.
[9] Elliot, J. (1991) Action Research for Educational Change, Open University Press

[10] Gaver, W. W., Beaver, J. \& Benford, S. (2003) Ambiquity as a resource for design. CHI'2003. ACM Press, NY, pp. 233-240.

[11] Gelernter, D. (1988): Deep Beauty. Chapter 1 in Machine Beauty: Elegance and the heart of Technology, Basic Books, New York, 1988

[12] Hallnäs, L. and Redström, J. (2002): Abstract information Appliances; Methodological Exercises in Conceptual Design of Computational Things, In: DIS2002: Serious reflection on designing interactive systems, pp. 105-116. ACM Press.

[13] Hallnäs, L. and Redström, J. (2002) From use to presence. On the expressions and aesthetics of everyday computational things. ACM Transactions on Computer-Human Interaction (ToCHI) 9(2) 106124.

[14] Hallnäs, L. and Redström, J. (2006): Computational Technology as a Design Material, Chapter 5.2 in Interaction Design: Foundations, Experiments. Textile Research Centre, Swedish School of Textiles, University College of Borås and Interactive Institute, 2006.

[15] Hopkins, D. (2002) A Teacher's Guide to Classroom Research, 3rd edition, Open University Press

[16] Janlert, L-E. and Stolterman (1997), E: The character of things, In: Design Studies. Vol.18, no.3, pages 297-317. Elsevier. 1997

[17] Lim, Y. et al (2007) Interaction gestalt and the design of aesthetic interactions, In: Proceedings of the 2007 conference on Designing pleasurable products and interfaces , 22-25 August 2007, Helsinki, Finland, ACM Publishing

[18] Lundgren, S. (2006) Facets of Fun: On the Design of Computer Augmented Entertainment Objects. Lic. thesis, Chalmers University of Technology, Gothenburg, Sweden.

[19] Lundgren, S. (2008) Treating and Teaching Aesthetics as Personality. Proceedings of NordiCHI 2008: Using Bridges, 18-22 October, Lund, Sweden.

[20] Manovich, L. (2006): Interaction as an aesthetic event, In: Reciever \# 17 (online magazine), Vodafone Group 2006

[21] Monö, Rune (1997) Design for Product Understanding, Liber, Sverige

[22] Petersen, M. G., Iversen, O., Krogh, P. and Ludvigsen, M. (2004) Aesthetic interaction: a pragmatist's aesthetics of interactive systems. Proc Designing Interactive Systems 2004. ACM Press, New York, pp. 269-276.

[23] Redström, J., Skog, T. and Hallnäs, L: (2000) Informative art: using amplified artworks as information displays. In: Proceedings of DARE 2000, Elsinore, Denmark

[24] Reeves, B and Nass, C.,(2002): Media and Personality, Part II in The media equation, CSLI Publications, Center for the study of Language and Information, Leland Stanford Junior University, 2002

[25] Schön, Donald (1983). The Reflective Practitioner: How Professionals Think in Action. Basic Books Inc, Reprinted by Ashgate Publishing Ltd, Aldershot, England.

[26] Shusterman, R. (1992) Pragmatist Aesthetics: Living beauty, Rethinking Art, Blackwell, Oxford

[27] Sundin, B. (2003) Estetik och Pedagogik, Bokförlaget Mareld, Sweden.

[28] Udsen, L. E. and Jørgensen, A. H (2005) The aesthetic turn. Unraveling recent aesthetic approaches to human-computer interaction, In: Digital Creativity 2005, Vol 16, No 4, pp 205-216

[29] Woodham, J. (1997) Twentieth Century Design, Oxford University Press.

[30] Ziff, Paul (1997/1984): Anything viewed, In: Feagin, S., and Maynard, P. (Eds.) Aesthetics, Oxford University Press 1997

Course home page: http://www.cs.chalmers.se/idc/ituniv/kurser/aoi/ 